\title{
A CONTRIBUIÇÃO DOS JORNAIS PARA A PRODUÇÃO HISTORIOGRÁFICA
}

\author{
NEWSPAPER CONTRIBUTION TO HISTORIOGRAPHIC PRODUCTION
}

\begin{abstract}
Augusto Russini ${ }^{1}$
RESUMO: Este artigo tem por objetivo abordar a importância dos jornais para a produção historiográfica. Em relação aos procedimentos metodológicos foi realizada uma pesquisa bibliográfica acerca da imprensa e do contexto histórico brasileiro (1937-1945) e uma análise de fontes documentais (jornais). Os jornais, entendidos como um meio de comunicação de massa, abordam em suas publicações um vasto número de assuntos/conteúdos, que permitem ao pesquisador aproximar-se de um contexto histórico, desvelando ideologias e interesses. Para a materialização deste estudo, primeiramente é apresentado o surgimento da imprensa escrita, e posteriormente uma reflexão sobre as influências exercidas no momento de sua elaboração e publicação. Para finalizar, são apresentadas reportagens dos jornais, Diário do Interior e A Razão, durante o Estado Novo (1937-1945) e, como suas publicações retratam e atuam, nesse recorte histórico, para legitimar os interesses políticos, econômicos e ideológicos do governo estadonovista.
\end{abstract}

Palavras-chave: Jornal. Imprensa. Historiografia.

ABSTRACT: This article aims to address the importance of newspapers for historiographical production. Regarding the methodological procedures, a bibliographical research was carried out about the press and Brazilian historical contexto (1937-1945) and an analysis of documentary sources (newspapers). The newpspapers, understood as a mens of mass communication, address in their publications a vast number of subjects/contentes, which allow the research to approach a historical contexto, unveiling ideologies and interests. For the materialization of this study, first the appearance of the written press is presented, and then a reflection on the influences exercised at the time of its elaboration and publication. Finally, reports from the newspapers Diário do Interior and A Razão, during the Estado Novo (1937-1945) are presented and, as their publications portray and act, in this historical section, to legitimize the political, economic ideological interests of the state government.

Keywords: Newspaper. Press. Historiography.

\section{INTRODUÇÃO}

Para identificar a potencialidade dos jornais como fonte de pesquisa histórica, é necessário buscar no surgimento da escrita pressupostos que permitam defini-la como modo de transmissão cultural. O homem desde seus primórdios tenta retratar os acontecimentos cotidianos por meio de imagens, gravuras, ou fragmentos escritos, para tanto, elabora diversas

\footnotetext{
${ }^{1}$ Graduação em História e Administração; Mestre em Ensino de Humanidades e Linguagens; Doutorando em Educação na Universidade Luterana do Brasil (ULBRA). Docente na Fundação Bradesco GravataíRS. E-mail: augustorussini.sm@gmail.com.
} 
maneiras de registrar seus conhecimentos e, consequentemente, desenvolver formas de comunicação.

Uma das formas de comunicação coletiva, criada pelo ser humano, são os jornais, retratando acontecimentos da vida cotidiana em seus mais diversos aspectos, perpassando pelo político, ideológico, econômico e cultural. Dessa forma, os jornais tornam-se uma importante e significativa fonte de pesquisa, para historiadores, antropólogos, cientistas sociais e estudiosos de diversos campos do conhecimento.

Contudo, a produção historiográfica baseada em jornais, apresenta algumas singularidades, pois as ideologias das classes detentoras do poder político e econômico estão inseridas em suas publicações e, podem mascarar a realidade social das classes abastadas do poder, ou desprovidas de recursos econômicos. Ao estudar um determinado cenário histórico, o pesquisador deve levar em consideração estes aspectos. Frente a estes pressupostos, estrutura-se o problema do presente estudo: como os jornais, entendidos como meio de comunicação em massa, podem colaborar para as pesquisas históricas? Nesse sentido, o objetivo deste estudo é descrever e refletir sobre as contribuições deste meio de comunicação de massa (jornal) para a produção historiográfica. Para tanto, é fundamental compreender a evolução da escrita, as ideologias políticas e econômicas presentes em suas publicações. O estudo finaliza com uma análise de reportagens publicadas nos jornais Diário do Interior e A Razão, com a finalidade de evidenciar como os periódicos retratam o período do Estado Novo (1937-1945), na cidade de Santa Maria, no estado do Rio Grande do Sul.

Em relação aos procedimentos metodológicos, o presente estudo estrutura-se como uma pesquisa bibliográfica, que segundo Marconi; Lakatos (2003, p. 18I) contempla as mais diversas produções, publicadas em diferentes plataformas, permitindo ao pesquisador não a "mera repetição do que já foi dito ou escrito sobre certo assunto, mas propicia o exame de um tema sob novo enfoque ou abordagem, chegando a conclusões inovadoras". Finalizada a etapa bibliográfica, o estudo volta-se para as fontes documentais, no caso os jornais Diário do Interior e A Razão, durante o Estado Novo (1937-1945), na cidade de Santa Maria, RS. Busca-se em Severino (2007, p. 122), o entendimento de pesquisa documental como a utilização dos mais variados tipos de documento, em sua versão ampliada, contemplando desde documentos impressos, filmes, jornais, fotos, gravações, entre outros, permitindo ao pesquisador acesso a conteúdos que "ainda não tiveram nenhum tratamento analítico, são ainda matéria-prima, a partir da qual o pesquisador vai desenvolver sua investigação e análise".

Dessa forma, trata-se se um estudo de abordagem qualitativa, que de acordo com Minayo (2002, p. 15) permite evidenciar o "dinamismo da vida individual e coletiva com toda a riqueza 
de significados dela transbordante”. A partir destas opções/estratégias metodológicas o artigo desenvolve-se em três etapas, a saber: A história da imprensa escrita; Os jornais e a produção historiográfica; e A influência dos jornais na produção historiográfica: Santa Maria/RS e o Estado Novo (1937-1945).

\section{A história da imprensa escrita}

O aparecimento dos primeiros escritos com o objetivo de transmissão cultural relatados pela História remete aos povos mesopotâmicos, mais precisamente aos Sumérios por volta do ano 3000 a. C. Estes desenvolveram um tipo de escrita próprio, representado por símbolos gravados em placas de argila e devido ao seu formato recebeu o nome de 'escrita cuneiforme'. Os egípcios por sua vez, também tiveram uma importante participação no processo de desenvolvimento da escrita, como forma de relatar seu cotidiano (aspectos comerciais, religiosos, científicos, jurídicos, culturais), para tanto elaboraram um sistema de escrita baseado em símbolos conhecido por 'hieróglifos'. Em um primeiro momento, os escribas (funcionários administrativos a serviço do faraó, responsáveis pelos registros escritos do povo egípcio) utilizavam placas de argila, mas devido à dificuldade de transportar os relatos, passaram a utilizar o papiro (FISCHER, 2009).

Estas formas de relatar a vida através de símbolos e sua constante adaptação a novas realidades, possibilitaram o surgimento distintas de formas de escrita, e estas mais elaboradas, como por exemplo, o alfabeto fenício, posteriormente serviu de inspiração para novos alfabetos como o grego e o arábico. O papiro e os pergaminhos (mais utilizado pelos arameus e fenícios) proporcionaram uma verdadeira revolução na história da escrita. Estes dois elementos foram utilizados com muito sucesso até o aparecimento do papel por volta do ano $105 \mathrm{~d}$. C. que logo se expandiu pelo mundo e passou a ter um importante papel no desenvolvimento das sociedades ao longo da história (THOMPSON, 1995).

Rapidamente difundido, o papel começou a ser aperfeiçoado/produzido em maior escala e a Itália assumiu um papel de vanguarda nesse processo. Ao retratar a indústria do papel, Thompson (1995, p. 230) elucida,

Em 1276 a primeira fábrica de papel italiana foi construída em Montefano. A fabricação italiana de papel se espalhou rapidamente; em I283 havia pelo menos I2 fábricas de papel em Fabriano, e no século VIX a Itália se tornou a principal produtora de papel para a Europa.

O aperfeiçoamento das técnicas de produção do papel concomitantemente ao desenvolvimento da impressão (técnica originária da China), possibilitou as primeiras impressões de textos europeus (século XIV), e com Gutenberg na metade do século XV, 
mediante a novas adaptações/tecnologias, ampliou a produção de textos difundindo idéias comerciais. Assim, no decorrer do século XV, a imprensa foi adquirindo um importante papel social proporcionando profundas modificações nos grandes centros da Europa. Estruturou-se, desta forma, como um eficaz meio de comunicação de massa, colaborando para o fortalecimento do comércio e disseminação das ideologias do Estado Nação (THOMPSON, 1995).

O desenvolvimento da imprensa como meio de comunicação de massa, contou ainda com Anton Koberg, que fundou em Nuremberg, no ano de 1470, uma grande empresa da imprensa que atingiu a marca de 236 publicações. William Caxton, rico comerciante inglês também merece referência, pois fundou em 1476, uma das mais bem sucedidas empresas do ramo na Inglaterra da época, publicando cerca de go livros, e depois de sua morte a empresa continuou com seu propósito publicando outras centenas de exemplares. Com uma vasta produção, a imprensa europeia dos séculos XVI, XVII e XVIII também comercializava panfletos, periódicos dos mais variados conteúdos defendendo interesses comerciais, políticos, militares, econômicos disseminando ideologias das classes dominantes (THOMPSON, 1995).

A presente retrospectiva histórica, foi realizada com o objetivo de compreender o papel da imprensa escrita no processo de comunicação de massas. Faz-se necessário conhecer a evolução da escrita como forma de 'transmissão cultural' para entender o jornal como imprescindível fonte de estudo para os historiadores do século XIX e XX.

Os jornais de circulação periódica ou determinada, com uma distribuição múltipla, só foi possível de se concretizar devido a uma série de transformações ocorridas durante os séculos XIX e XX. Dentre os fatores que permitiram a difusão deste mecanismo de comunicação, destaca-se a redução dos custos dos exemplares, assomado a diminuição do número de analfabetos, presentes nos grandes centros urbanos. Juntamente, com o número elevado de publicações, seu conteúdo sofreu algumas modificações, tornando-se mais agradável ao leitor e desta maneira atingindo amplas camadas da sociedade, não mais apenas a elite intelectual e econômica. Para manter a popularidade dos jornais, assuntos do cotidiano começaram a ser retratados, como por exemplo, os crimes, a violência sexual, jogos, entre outros, sendo este conteúdo divido com espaços para anúncios comerciais (THOMPSON, 1995).

A partir do século $\mathrm{XX}$, em paralelo ao crescimento no número de tiragens, verifica-se a diminuição do número de empresas jornalísticas. Entende-se, que a indústria da mídia está se estruturando em torno de grupos economicamente poderosos e de número reduzido, defendendo interesses comerciais, econômicos e políticos de setores constituintes da sociedade. $O$ desenvolvimento de uma série de novas tecnologias possibilitou aos jornais noticiarem acontecimentos de amplas dimensões, sendo a mais importante à publicação de notícias 
internacionais nos grandes centros, emergindo as chamadas 'agências de notícias' que através do telégrafo, do rádio e da televisão, passavam com uma considerável rapidez os acontecimentos ocorridos para os centros de redação destes jornais (THOMPSON, 1995).

Apesar de amplo alcance, a empresa jornalística ficou restrita ao domínio de poucos grupos que providos de recursos econômicos, adaptaram sua elaboração conforme seus interesses comerciais, criando um público que em sua maioria acompanha, de maneira despercebida, os acontecimentos sociais que o cercam.

\section{Os jornais e a produção historiográfica}

A produção historiográfica utiliza várias fontes para tentar estudar o passado e múltiplas formas para se aproximar do objeto de pesquisa, para tanto recorre a recursos como atos tabelionais, cartas, testamentos, vestígios arqueológicos, história oral, entre outros (SCHIMIDT; CAINELLI, 2004). Na incessante busca por fontes históricas, o jornal adquire um valor imprescindível para a produção historiográfica, devido a variedades de informações, reunidas em um único exemplar (LOSNAK, 2004).

O jornal, ou periódico, é composto geralmente por notícias, artigos e reportagens construídas por jornalistas que utilizam diversas estratégias para chegar às fontes (ou informações) para sua elaboração. Porém, os jornalistas são sujeitos históricos e perpassam em suas produções as ideologias que são adeptos, ou escrevem para um governo ou grupo privado, que procuram afirmação/aceitação em um determinado local. Para uma melhor compreensão da importância social do jornal, como meio de comunicação de massas, faz-se necessário definir o que é um jornal, e para tanto Losnak (2004, p. 8I), esclarece:

O jornal é uma empresa privada que se propõe a informar o leitor sobre as várias dimensões de acontecimentos de uma sociedade, possuindo uma linha editorial e comercial. Nele, reúnem-se redatores e jornalistas em geral editores e proprietários com propostas divergentes e convergentes.

Compreendido, como meio de comunicação de massa, o jornal tem sua produção influenciada pelo momento histórico em que está inserido. Assim, no momento de organização/formulação de suas publicações, defende interesses e de forma objetiva chega ao leitor apresentando argumentos bem fundamentados (dados estatísticos, informações, detalhes) moldando seu público a partir das ideologias/ interesses definidos.

A influência dos jornais na produção historiográfica: santa maria, RS e o Estado Novo (19371945)

A utilização dos jornais como fonte de pesquisa histórica permite ao historiador aproximar-se e 'construir' conhecimentos de um espaço temporal proposto. Contudo, a produção 
historiográfica baseada em informações jornalísticas apresenta algumas peculiaridades, como por exemplo, a influência das ideologias políticas do momento e os interesses comerciais das empresas proprietárias deste veículo de comunicação de massa.

Dessa maneira, a partir de reportagens extraídas do jornal Diário do Interior, entre os anos de 1937 -1945, tentar-se-á perceber algumas ideologias políticas do Estado Novo, como a exaltação de símbolos nacionais, a transição de uma economia agropecuária para uma economia comercial e industrial, o combate ao comunismo, desenvolvimento logístico (estradas e linhas telefônicas) retratados em Santa Maria, no estado do Rio Grande do Sul, no contexto político estadonovista.

Dentre as ideologias difundidas pelo Estado Novo (1937-1945), a construção de uma unidade nacional era um dos grandes desejos de Getúlio Vargas, para tanto procurou-se através da exaltação de símbolos nacionais legitimar esse processo, que coincide com a busca de um poder forte e centralizador (FAUSTO, 200I). Essa influência estadonovista, pode ser percebida na comunidade de Santa Maria, por meio da manchete de capa do jornal Diário do Interior, em 2I de novembro de 1937:

O dia da bandeira, em Santa Maria, foi um acontecimento inédito de brasilidade. O nosso povo homenageou condignamente o símbolo estremecido da pátria. Importante cerimônia cívico-religiosa na Catedral e também majestosa e extraordinária concentração cívica realizada no principal logradouro público da cidade (p. I).

Nesse sentido, a comunidade de Santa Maria se inseriu na ideologia de formação cívica do governo Varguista, dignificando os símbolos nacionais realizando eventos que estimulavam o patriotismo. O período histórico referido, também é marcado pelo avanço tecnológico e pela proposta de urbanização nacional. Santa Maria, RS, por sua vez também se inseriu neste processo, como é confirmado pelo período Dário do Interior, do dia i6 de abril de 1939:

Entrou em funcionamento o moderno serviço de telefonia automático da Companhia Telefônica Rio-Grandense [...]. Revestiu-se de solenidade o ato de inauguração da Central Telefônica Rio-Grandense que acaba de montar nesta cidade, para cumprir o contrato que em fins de 1937 assinou com a prefeitura municipal. Compareceram ao ato autoridades civis e militares, representantes da imprensa e das classes conservadoras (p. 2).

Esse cenário de transformação da realidade brasileira, antes tipicamente agroexportadora para uma sociedade urbana e industrial, também é vivenciado pela comunidade santa-mariense, que para se adequar ao plano de desenvolvimento nacional posto em prática pelo governo de Getúlio Vargas, concretizando obras de logística (construção de rodovias). Um dos exemplos, a ligação de Santa Maria a São Sepé, sendo estas obras, acompanhadas pelas autoridades do governo de Vargas, como descrito pela imprensa local, no jornal Diário do Interior, em 9 de 
janeiro de 1940:

O coronel Cordeiro de Farias acompanhado pelo Prefeito Municipal o Dr. Xavier da Rocha e outras autoridades, visitou de automóvel a estrada Santa Maria - São Sepé em construção pelo Departamento Autônomo de Estradas e Rodagens. A excursão se estendeu até o Passo das Tropas, onde a caravana estacionou e o coronel Cordeiro de Farias recebeu do Dr. Weimann Peixoto Pinto, chefe da $4^{-}$Presidência todas as informações sobre esta importante rodovia, que ligará esta cidade a São Sepé e Caçapava. Atualmente essa estrada está sendo empedrada. Durante a informação, o engenheiro Weimann Pinto declarou que a obra já se encontra em condições de tráfego, faltando apenas algumas obras de arte para ficar completa (p. 2).

O Estado Novo, caracterizava-se também pela atuação do Departamento de Imprensa e Propaganda (DIP), que exercia uma censura sobre os meios de comunicação e estimulava a disseminação das ideologias que sustentavam a permanência do regime varguista. Em todo o Brasil, várias campanhas contra o comunismo foram colocadas em ação, e este combate ao comunismo teve por característica a utilização dos recursos de comunicação em massa como o rádio e os jornais (FAUSTO, 200I). O jornal Diário do Interior, também manteve espaço em suas publicações para a disseminação desta ideologia anticomunista evidenciando inúmeras matérias, como por exemplo, a publicada no dia 12 de novembro de 1937:

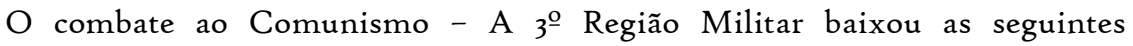
instruções sobre as atividades comunistas: ter maior rapidez nas investigações em torno de atividades comunistas de elementos militares e civis e que os delegados e subdelegados ou a quem for responsável de realizar as referidas investigações procedam à sindicância de forma minuciosa [...] concluindo qualquer sindicância positivamente, pela responsabilidade de atividades comunistas, deverão as autoridades proceder imediatamente mandando os culpados à Chefia de Polícia Militar, para ulteriores providências processuais (p. 2).

Ao passo em que o Estado Novo apresentava sinais de enfraquecimento, a nível nacional, sobretudo a partir da participação ao lado dos Aliados na Segunda Guerra Mundial, onde lutava pela liberdade e a democracia contra os fascismos no cenário internacional, mantendo um regime ditatorial internamente, gerava contradições e pautas relativas a democratização ganhavam força e reuniam adeptos (CORSI, 1996). Nessa conjuntura, conteúdos antes considerados contrários aos interesses de Getúlio Vargas e da política estadonovista passam a ganhar destaque na imprensa local, como por exemplo, a abordagem realizada sobre o comício queremista ${ }^{2}$, ocorrido em Santa Maria, publicado pelo jornal A Razão, do dia 4 de outubro de 1945

${ }^{2}$ Queremismo foi um movimento surgido por volta de maio de 1945, tendo por objetivo defender a permanência de Getúlio Vargas no poder, como presidente da República. Fonte: https://cpdoc.fgv.br/producao/dossies/AEraVargasi/anos37-45/QuedaDeVargas/Queremismo. Acesso em: 23 dez. 2020. 
Realizou-se ontem o comício "queremista" anunciado em todo o país, simultaneamente, sob a legenda "Para a Constituinte com Getúlio Vargas". Segundo informações radiofônicas na noite, no Rio de Janeiro e em São Paulo o comício redundou em fracasso (...). Em Santa Maria, foi registrado assistência reduzida e pouco entusiasta (p. I).

A abordagem das reportagens publicadas no jornal Diário do Interior e A Razão, entre os anos de 1937 a 1945, permitem pensar a imprensa jornalística influenciada pelo momento histórico. A partir das análises, foi possível perceber a presença das ideologias políticas difundidas no Estado Novo, em nível nacional, presentes no local, na cidade de Santa Maria, RS. Nitidamente, os jornais em destaque, perpassaram ao público leitor as ideias das classes dirigentes do país, no momento de afirmação das políticas propostas pelo presidente Getúlio Vargas, bem como seu processo de enfraquecimento.

\section{CONSIDERAÇÕES FINAIS}

A utilização de jornais como fonte de pesquisa histórica é sem dúvida um importe recurso. Os diversos assuntos abordados em suas publicações permitem aos historiadores observarem uma determinada sociedade em um período temporal delimitado sobre diversos ângulos. A abordagem em jornais, pode revelar as diversas estruturas subjetivas que compõem a realidade social, ou seja, o poder exercido pelas ideologias adaptadas ao interesse comum das classes que detém o poder político e econômico.

Os membros da empresa jornalística (redatores, jornalistas, editores, repórteres, empresários) perpassam os interesses políticos, ideológicos e econômicos delimitados para o público leitor de forma sutil e objetiva, transformando este veículo de comunicação de massa em um forte instrumento de afirmação e de disseminação dos interesses das elites. Tais afirmações podem ser percebidas durante as análises das matérias publicadas durante o Estado Novo (19371945) nos jornais Diário do Interior e A Razão, nas quais são repassadas ao público leitor as principais ideologias do governo varguista: desenvolvimento urbano, formação de um Estado forte, com um poder centralizado, o combate ao comunismo e seu processo de enfraquecimento, uma vez que a manutenção de Getúlio Vargas, como presidente da República, mostrava-se desalinhado com os interesses ideológicos do pós Segunda Guerra Mundial.

\section{Referências}

CORSI, F. L. O fim do Estado Novo e as disputas em torno da política econômica. Revista de Sociologia e Política. Curitiba, no 6/7, 1996, p. 25-36. Disponível em: https://revistas.ufpr.br/rsp/article/view/39336. Acesso em 23 dez. 2020.

FAUSTO, B. História concisa do Brasil. São Paulo: USP, 2001. 
FISCHER, S. R. História da escrita. [trad. Mirna Pinsky]. São Paulo: UNESP, 2009.

LOSNAK, C. J. Polifonia Urbana Imagens e Representações Bauru 1950-1980. Bauru: Edusc, 2004, p. 8I-III.

MARCONI, M. A.; LAKATOS, E. M. Fundamentos de metodologia científica. $5^{\circ}$ ed. São Paulo, Atlas, 2003.

MINAYO, M. C. S. Ciência, técnica e arte: o desafio da pesquisa social. In: MINAYO, M. C. S. (org) Pesquisa social: teoria, método e criatividade. 2Iํe ed. Petrópolis, Vozes, p. 09-30, 2002.

RUSSINI, A. Santa Maria e a Política Estadonovista 1947-1945. Trabalho Final de Graduação UNIFRA, 2005

SEVERINO, A. J. Metodologia do trabalho científico. 23ํe․ São Paulo, Cortez, 2007.

SHIMIDTH, M.A; CAINELLI, M. Ensinar história. São Paulo, Scipione, 2004.

THOMPSON, J. B. Ideologia e Cultura Moderna: Teoria Social Crítica na era dos Meios de Comunicação de Massa. Petrópolis: Vozes, 1995.

Diário do Interior. Santa Maria, 12 novembro de 1937, p. 2.

Diário do Interior. Santa Maria, 2I novembro de 1937, p. I.

Diário do Interior. Santa Maria, i6 de abril de 1939, p. 2.

Diário do Interior. Santa Maria, 9 de janeiro de 1940, p. 2.

A Razão. Santa Maria, 4 de outubro de 1945. 